\begin{tabular}{|c|l|}
\hline Title & A Simple Method for the Preparation of Stainless and Highly Pure Trichloroacetimidates \\
\hline Author(s) & Ikeuchi, Kazutada; Murasawa, Kentaro; Y amada, Hidetoshi \\
\hline Citation & $\begin{array}{l}\text { Synlett, 30(11), 1308-1312 } \\
\text { https://doi.org/10.1055/50037-1611551 }\end{array}$ \\
\hline Issue Date & 2019-07 \\
\hline Doc URL & http://hdl.handle.net/2115/78010 \\
\hline Type & article (author version) \\
\hline File Information & Synlett 30(11) 1308.pdf \\
\hline
\end{tabular}

Instructions for use 


\section{A simple method for preparation of stainless and highly pure trichloroacetimidate}

\author{
Kazutada Ikeuchi $*_{a, b}$ \\ Kentaro Murasawa a \\ Hidetoshi Yamada*a \\ a School of Science and Technology, Kwansei Gakuin \\ University, 2-1, Gakuen, Sanda, 669-1337, Japan \\ ${ }^{b}$ Department of Chemistry, Faculty of Science, Hokkaido \\ University, West 8, North 10, kita-ku, Sapporo, 060-0810, \\ Japan \\ ikeuchi@sci.hokudai.ac.jp
}

hidetosh@kwansei.ac.jp

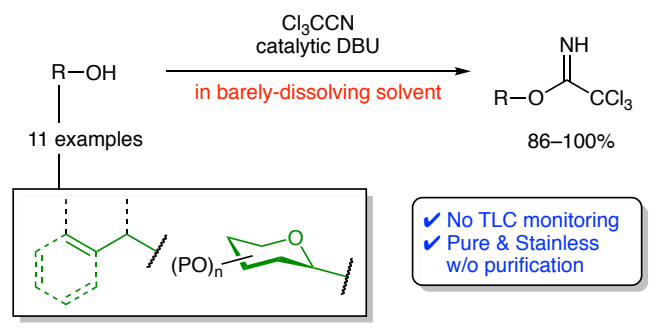

donors in oligosaccharide syntheses, such as the Schmidt glycosylation (Scheme 1c). ${ }^{6}$

A major driving force in the aforementioned reactions is the instability of the TCAIs, which transform into more stable trichloroacetamides. This instability frequently causes degradation even in their preparation, especially during chromatographic purification on silica gel; therefore, this purification should ideally be avoided. However, crude TCAIs are often stained when they are prepared by standard procedures (Scheme 2). Although, in general, staining is not considered to affect the purity of the TCAIs, the pigment is actually a byproduct (or byproducts) of their synthesis, resulting in some level of contamination. Thus, staining should be avoided. Herein, we report an improved method to prepare TCAIs with sufficient purity without staining during their crude form.

$\mathrm{Cl}_{3} \mathrm{CCN}$, are widely used in organic synthesis. For instance, benzyl (Bn)- and $p$-methoxybenzyl (PMB)-TCAIs (1 and 2) are utilized when installing corresponding protective groups (Scheme 1a).1,2 Because the installation is implemented under acidic reaction conditions, the method is an alternative to the Williamson ether synthesis that requires basic reaction conditions. ${ }^{3}$ In addition, TCAIs derived from allyl alcohols act as reactants in the Overman rearrangement (Scheme $1 b)^{4}$, which incorporates a nitrogen atom into a hydrocarbon skeleton in natural product synthesis. ${ }^{5}$ Furthermore, glycosyl TCAIs are standard glycosyl

$$
\text { a) Alcohol protection }
$$

b) Overman rearrangement

$$
\overbrace{\mathrm{CCl}_{3}}^{\longrightarrow} \stackrel{\text { heat }}{\longrightarrow}
$$

c) Schmidt glycosylation

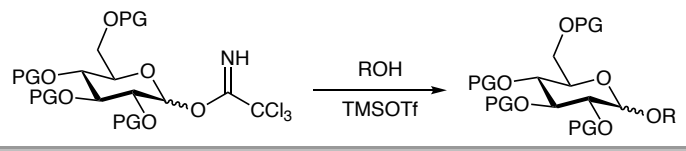

Scheme 1 Typical transformations using TCAls

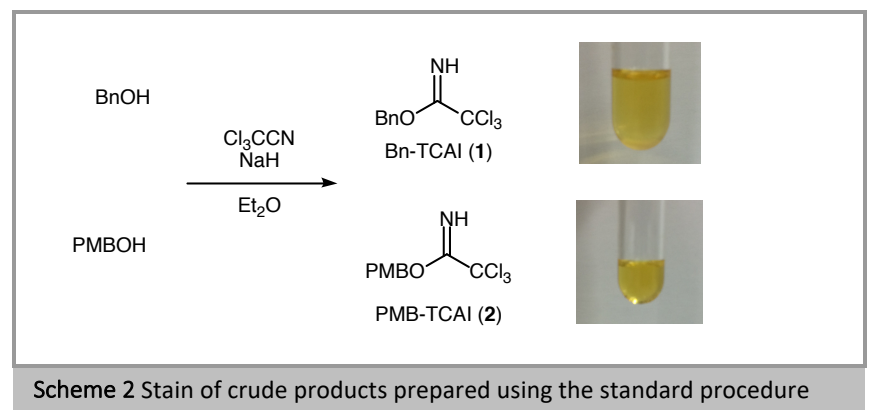

In general, the TCAIs are prepared by treating an alcohol with $\mathrm{Cl}_{3} \mathrm{CCN}$ in the presence of a catalytic amount of a base in a solvent. Two standard base/solvent combinations are $\mathrm{NaH} / \mathrm{Et}_{2} \mathrm{O}^{7-10}$ and $\mathrm{DBU} / \mathrm{CH}_{2} \mathrm{Cl}_{2} \cdot{ }^{11-14}$ Using $\mathrm{NaH} / \mathrm{Et}_{2} \mathrm{O}$ involves a potential risk of contamination by the mineral oil that is supplied with $\mathrm{NaH}$. In addition, the method stains the products (Scheme 2). By contrast, using DBU $/ \mathrm{CH}_{2} \mathrm{Cl}_{2}$ is preferable because $\mathrm{DBU}$ can be removed by liquid-liquid extraction (LLE) with an aqueous acid. However, this method also stains the products (Scheme 3, the fifth vial from the right end).

A clue to removing the stain was obtained through the screening of reaction solvents for the preparation of PMB-TCAI (2), the instability of which is known (Scheme 3).15 In each trial, a mixture of $\mathrm{PMBOH}$ and $\mathrm{Cl}_{3} \mathrm{CCN}$ (1.1 equiv) with DBU (10 mol\%) in a solvent was stirred at $0{ }^{\circ} \mathrm{C}$ for $30 \mathrm{~min}$, followed by LLE and 
concentration under reduced pressure to obtain the crude product 2. Acetone, pyridine, THF, DMF, MeCN, toluene, $\mathrm{CH}_{2} \mathrm{Cl}_{2}$, EtOAc, $\mathrm{CHCl}_{3}, \mathrm{Et}_{2} \mathrm{O}$, or hexane was used as the reaction solvent. Among them, the use of $\mathrm{CH}_{2} \mathrm{Cl}_{2}$ with $\mathrm{DBU}$ is well known, ${ }^{12}$ which provided a pale yellow crude product; therefore, purification using a short silica gel or an $\mathrm{Al}_{2} \mathrm{O}_{3}$ column is required to obtain a colorless 2 as reported. ${ }^{12} \mathrm{Et}_{2} \mathrm{O}$, a preferred reaction solvent for the synthesis of $\mathbf{2}$ when catalytic $\mathrm{NaH}$ was used as the base, produced a stainless crude product. However, the starting material remained due to the slow reaction rate (see page S7 of the supporting information). Using acetone, pyridine, THF, DMF, $\mathrm{MeCN}$, or toluene instead of $\mathrm{CH}_{2} \mathrm{Cl}_{2}$ intensified the staining of the crude product. The reaction in EtOAc also produced a slightly yellow crude product. Although a colorless crude product was obtained when $\mathrm{CHCl}_{3}$ was used as the solvent, a byproduct was detected (see page S15 of the supporting information). This byproduct seemed to be ethyl TCAI derived from ethanol, which had been added to $\mathrm{CHCl}_{3}$ as a stabilizer. Surprisingly, although hexane hardly dissolved $\mathrm{PMBOH}$, the reaction proceeded smoothly to produce $\mathbf{2}$ in a $96 \%$ yield without staining the product. 16

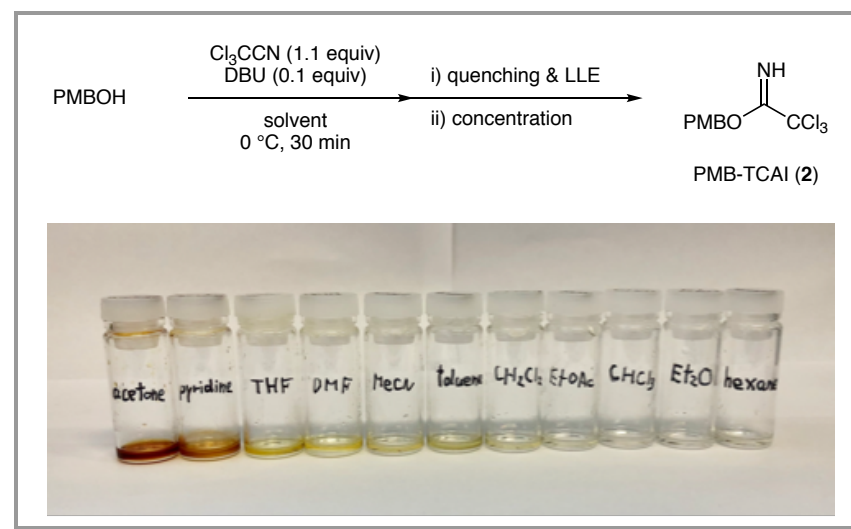

Scheme $\mathbf{3}$ Color of the crude $\mathbf{2}$ when varying reaction solvent ${ }^{a, b} a$ The used reaction solvent was written on each vial. ${ }^{b} \mathrm{DMF}=\mathrm{N}, \mathrm{N}$-dimethylformamide, $\mathrm{THF}=$ tetrahydrofuran.

The use of hexane presented another advantage; namely, the progress of the reaction could be detected visually. Because of the low solubility of $\mathrm{PMBOH}$ in hexane, the reaction mixture was a suspension in the beginning. In contrast, the mixture became a solution at the end of the reaction, as product $\mathbf{2}$ easily dissolves into hexane. This visual detection was useful since $\mathbf{2}$ decomposed on silica gel to produce $\mathrm{PMBOH}$. Even after completion of the reaction, TLC indicated the spot of $\mathrm{PMBOH}$. In this case, typical TLC monitoring was unsuitable; hence, this visual change could be a useful index for estimating the endpoint of the reaction. Such visual change may be applied to automatous monitoring of the reaction using light transmission.

The reaction conditions using hexane as the solvent were applicable when the scale was increased and when heptane was used to give unstained and substantially pure $\mathbf{1}$ and $\mathbf{2}$ (Scheme 4). Thus, at the $500 \mathrm{mg}$ and $1.0 \mathrm{~g}$-scales, treatment of $\mathrm{Cl}_{3} \mathrm{CCN}$ with $\mathrm{BnOH}$ and $\mathrm{PMBOH}$, respectively, in the presence of catalytic DBU in hexane or heptane at $0{ }^{\circ} \mathrm{C}$ produced $\mathbf{1}$ and $\mathbf{2}$, both in quantitative yields as colorless liquids. Hexane has neurotoxicity ${ }^{17}$ and an electrostatic ignition hazard..$^{18}$ Therefore, substitution with heptane is recommended for large-scale synthesis. ${ }^{19}{ }^{1} \mathrm{H}$ NMR and ${ }^{13} \mathrm{C}$ NMR spectra showed that the products were substantially pure after LLE without further purifications (see page S20-27 of the supporting information).

(a) $500 \mathrm{mg}$ scale

\begin{tabular}{lll}
$\mathrm{BnOH}$ & $\begin{array}{c}\mathrm{Cl}_{3} \mathrm{CCN}(1.1 \text { equiv) } \\
\mathrm{DBU}(0.1 \text { equiv) }\end{array}$ & $\mathbf{1}(100 \%)$ \\
\cline { 2 - 2 } & hexane, $0^{\circ} \mathrm{C}$ & $\mathbf{2}(100 \%)$
\end{tabular}

(b) $1.0 \mathrm{~g}$ scale

$\begin{array}{lll}\mathrm{BnOH} & \stackrel{\mathrm{Cl}_{3} \mathrm{CCN}(1.1 \text { equiv) }}{\mathrm{DBU}(0.1 \text { equiv) }} \underset{\mathrm{PMBOH}}{ } & \mathbf{1}(98 \%) \\ & \text { heptane, } 0{ }^{\circ} \mathrm{C} & \mathbf{2}(99 \%)\end{array}$

Scheme 4 Syntheses of Bn- and PMB-TCAls (1 and 2): (a) at 500 mg scale in hexane, (b) at $1.0 \mathrm{~g}$ scale in heptane

The typical procedure was as follows (Figure 1). The reaction could be carried out in the open air. Strict anhydrous settings were not necessary. DBU (10 mol\%) was added to a stirred mixture of a reactant ( $\mathrm{BnOH}$ or $\mathrm{PMBOH}$ ) and $\mathrm{Cl}_{3} \mathrm{CCN}$ (1.1 equiv) in hexane or heptane (ca. $0.4 \mathrm{M}$ ) at $0{ }^{\circ} \mathrm{C}$. The purity of the used hexane or heptane was $\geq 95.0 \%$ and $\geq 98.5 \%$, respectively. At the beginning of the reaction, the reaction mixture was a suspension (Figure 1, photograph i). The reaction finished in almost $30 \mathrm{~min}$. At the end of the reaction, the mixture changed to a solution (Figure 1, photograph ii). A yellow and undissolved substance frequently appeared, sticking to the glassware wall when the scale of the reaction was $1.0 \mathrm{~g}$. The mixture was diluted at $0{ }^{\circ} \mathrm{C}$ with hexane or heptane (the same solvent used for the reaction), the volume of which was approximately equal to that of the reaction solvent. Subsequently, saturated aq $\mathrm{NH}_{4} \mathrm{Cl}$ (a volume nearly equal to the sum of the reaction and diluted solvents) was added at the same temperature. The mixture was transferred to a separatory funnel. Subsequently, LLE was conducted. After removal of aqueous layer, the organic layer was again washed with saturated aq $\mathrm{NH}_{4} \mathrm{Cl}$. The LLE process removed DBU and the yellow byproduct into the aqueous layer. The separated organic layer was dried over $\mathrm{Na}_{2} \mathrm{SO}_{4}$ and filtered. The concentration of

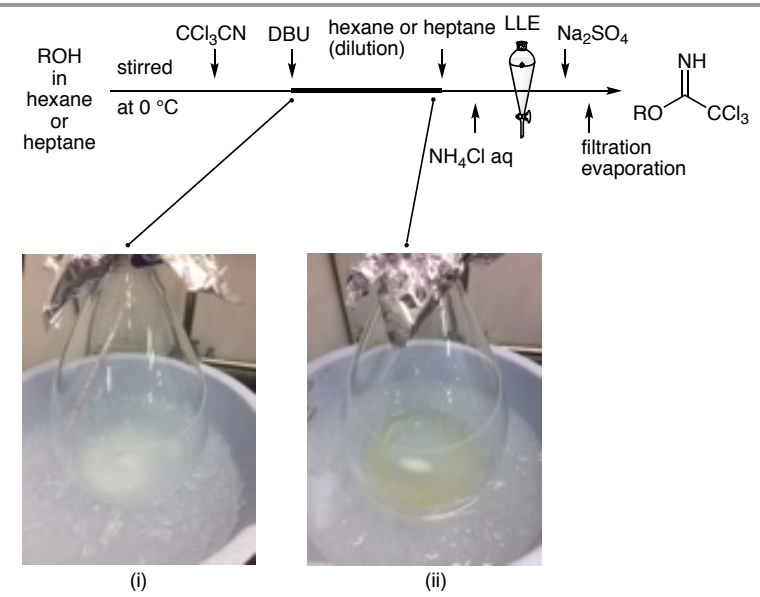

Figure 1 Reaction procedure when heptane was used for the synthesis of $\mathbf{2}$ The appearance is similar when $\mathbf{1}$ is synthesized and when hexane is used. (i) At the beginning of the reaction, the mixture is a suspension. (ii) At the end of the reaction, the mixture is a solution. The yellow pigment, which moves to the aqueous layer in the LLE process, is not $\mathbf{2}$. 
the filtrate using a rotary evaporator gave $\mathbf{1}$ or $\mathbf{2}$ as a colorless liquid in a higher than $98 \%$ yield. ${ }^{20}$ Note that the crude product was occasionally stained when the reaction was performed at room temperature. Additionally, the quenching of the reaction should be conducted immediately after the reaction is completed because keeping the reaction at $0{ }^{\circ} \mathrm{C}$ for a long time also stains the crude product.

The advantages of the method were the following. (1) The products were colorless and pure after LLE without further purification. (2) The yields were more than 98\%. (3) The obtained TCAIs 2 could be preserved at $-10{ }^{\circ} \mathrm{C}$ for more than a year without degradation (see page S28 of the supporting information). (4) The operation was easy, allowing open air execution without concern for strict anhydrous conditions and the grade of the solvents.

The method using hexane as the solvent could be applied to the syntheses of various benzylic and allylic TCAIs (Scheme 5). ${ }^{21}$ Treatment of 3,4-dimethoxybenzyl alcohol (3a) and 2,4,6trimethylbenzyl alcohol $(\mathbf{3 b})$ with $\mathrm{Cl}_{3} \mathrm{CCN}$ in the presence of a catalytic amount of DBU uneventfully afforded $\mathbf{4 a}$ and $\mathbf{4 b}$, both of which are considered more unstable than PMB-TCAI (2). 4Bromobenzyl TCAI (4c) was also prepared without reducing the yield. Application of this method to cinnamyl alcohol (3d) and geraniol (3e), primary allylic alcohols, provided the corresponding TCAIs $\mathbf{4 d}$ and $\mathbf{4 e}$ in excellent yields. The use of a secondary allylic alcohol 3f also gave $4 \mathbf{f}$ in $87 \%$ yield. The reaction using cyclohex-2-ene-1-ol (3g) proceeded smoothly, but the crude $\mathbf{4 g}$ was stained orange. However, the result was at least better than that of the one produced when using $\mathrm{CH}_{2} \mathrm{Cl}_{2}$, which gave $\mathbf{4 g}$ as a brown crude product (see page $\mathrm{S} 35$ of the supporting information). The reaction of linalool (3h) did not occur due to steric hindrance.

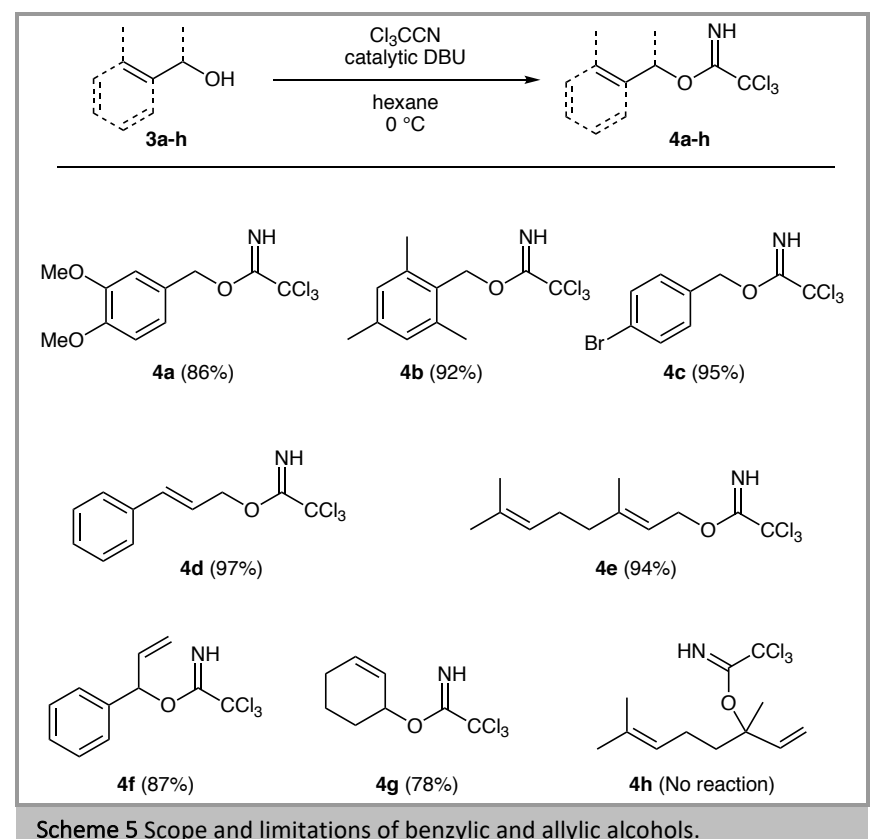

Scheme 5 Scope and limitations of benzylic and allylic alcohols.

Solvent selection is a key factor toward application to glycosyl TCAIs (Scheme 6). In the case of 2,3,4,6-tetra- $O$-acetyl- $\beta$-Dglucopyranose (5), the aforementioned reaction conditions provided $\mathbf{6}$ at only a $5 \%$ yield (Scheme 6a). The poor yield was the result of the extremely low solubility of $\mathbf{5}$ in hexane 0.6 $\mathrm{mg} / \mathrm{mL}$ ). Changing the solvent from hexane to $t$-BuOMe improved the yield. The solubility of $\mathbf{5}$ in $t$-BuOMe was still low $(20 \mathrm{mg} / \mathrm{mL})$; however, the reaction proceeded easily without staining to give the desired TCAI 6 in a $98 \%$ yield as a mixture of anomers $(\alpha / \beta=11 / 1){ }^{21}$ This result suggests that the use of a reaction solvent where a reactant can be barely dissolved is the key point in synthesizing stainless TCAI. Additional examinations using a Bn protected glucose $\mathbf{7}$ and a mannofuranose derivative 8 supported this suggestion (Scheme $6 \mathrm{~b}$ ). ${ }^{21}$ Because the solubility of $\mathbf{7}$ and $\mathbf{8}$ in hexane and toluene was 0.2 and $5.5 \mathrm{mg} / \mathrm{mL}$, and 0.2 and $23 \mathrm{mg} / \mathrm{mL}$, respectively, we prepared their TCAIs in toluene. No reaction proceeded at $0{ }^{\circ} \mathrm{C}$, but 7 gave stainless 9 at room temperature in a $98 \%$ yield. On the other hand, 8 easily reacted at $0{ }^{\circ} \mathrm{C}$ to give only $\alpha-10$ in a $96 \%$ yield. Unfortunately, our method was not suited to a glucosamine derivative $\mathbf{1 1}$ (Scheme 6c). Because 11 barely dissolved in EtOAc (12 mg/mL), EtOAc was used as the solvent. Despite observing that the reaction mixture changed from a suspension to a clear solution, the reaction did not complete to give a 3:2 mixture of $\beta-\mathbf{1 2}$ and $\mathbf{1 1}$. This reason might be attributed to the low reactivity of $\mathbf{1 1}$ due to the decrease of nucleophilicity of the hydroxy group induced by the presence of electron withdrawing protecting groups and a hydrogen bond in the phthaloyl group.

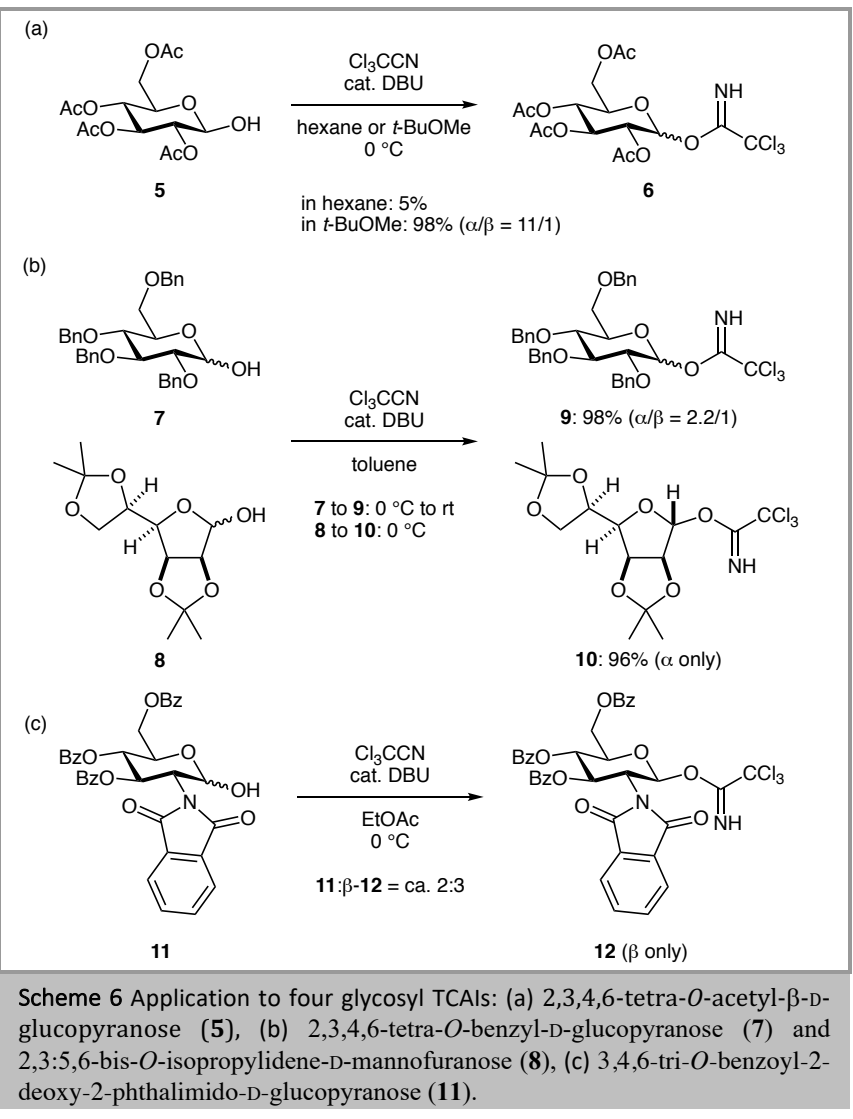

In summary, we developed a method for obtaining stainless TCAI compounds without purification by chromatography or distillation. The crucial aspect was the selection of a solvent that barely dissolved the reactant alcohol. The method effectively provided Bn- and PMB-TCAIs (1 and 2), commonly used for protecting alcohols. We also confirmed that the method was applicable not only for the gram-scale synthesis of $\mathbf{1}$ and $\mathbf{2}$, but also for the preparation of various allylic and glycosyl TCAIs (4a- 
$\mathbf{f}, \mathbf{6}, \mathbf{9}, \mathbf{1 0}$ ). This method is proposed here as a new standard procedure for the preparation of the TCAIs.

\section{Funding Information}

The MEXT in Japan supported the program for the Strategic Research Foundation at Private Universities (S1311046), and JSPS KAKENHI (Grant Number JP16H01163 in Middle Molecular Strategy, and JP16KT0061) partly supported this work.

\section{Supporting Information}

Yes

\section{Primary Data}

No

\section{References and Notes}

(1) For Bn-TCAI, see: (a) Eckenberg, P.; Groth, U.; Huhn, T.; Richter, N.; Schmeck, C. Tetrahedron 1993, 49, 1619. (b) Boa, A. N.; Jenkins, P. R. In Encyclopedia of Reagents for Organic Synthesis, 2nd ed.; Paquette L. A., Crich, D., Fuchs, P. L., Molander, G. A., Eds.; Wiley: New York, 2009; Vol. 2, 680.

(2) For PMB-TCAI, see: (a) Nakajima, N.; Horita, K.; Abe, R.; Yonemitsu, O. Tetrahedron Lett. 1988, 29, 4139. (b) Wuts, P. G. M. In Encyclopedia of Reagents for Organic Synthesis, 2nd ed.; Paquette L. A., Crich, D., Fuchs, P. L., Molander, G. A., Eds.; Wiley: New York, 2009; Vol. 8, 6598 .

(3) Wang, Z. Ed.; In Comprehensive Organic Name Reactions and Reagents; Wiley: New York, 2009; Vol. 3, 3026.

(4) Overman, L. E.; Carpenter, N. E. Org. React. 2005, 66, 1.

(5) Fernandes, R. A.; Kattanguru, P.; Gholap, S. P.; Chaudhari, D. A. Org. Biomol. Chem. 2017, 15, 2672.

(6) (a) Schmidt, R. R.; Michel, J. Angew. Chem. Int. Ed. 1980, 19, 731. (b) Zhu, X.; Schmidt, R. R. Angew. Chem. Int. Ed. 2009, 48, 1900.

(7) For examples of preparation of Bn-TCAI, see: (a) Lonca, G. H.; Ong, D. Y.; Tran, M. T. H.; Tejo, C.; Chiba, S.; Gagosz, F. Angew. Chem. Int. Ed. 2017, 56, 11440. (b) Li, C.; Li, W.; Wang, J. Tetrahedron Lett. 2009, 50, 2533. (c) Trappeniers, M.; Goormans, S.; Van Beneden, K.; Decruy, T.; Linclau, B.; Al-Shamkhani, A.; Elliott, T.; Ottensmeier, C.; Werner, J. M.; Elewaut, D.; Van Calenbergh, S. ChemMedChem 2008, 3, 1061. (d) Wessel, H.-P.; Iversen, T.; Bundle, D. R. J. Chem. Soc. Perkin Trans. 1 1985, 2247.

(8) For examples of preparation of PMB-TCAI, see: a) Green, R. A.; Jolley, K. E.; Al-Hadedi, A. A. M.; Pletcher, D.; Harrowven, D. C.; Frutos, O. D.; Mateos, C.; Klauber, D. J.; Rincoń, J. A.; Brown, R. C. D. Org. Lett. 2017, 19, 2050. (b) Kumar, R.; Rej, R. K.; Halder, J.; Mandal, H.; Nanda, S. Tetrahedron: Asymmetry 2016, 27, 498. (c) Wadavrao, S. B.; Ghogare, R. S.; Narsaiah, A. V. Synthesis 2015, 47, 2129. (d) Chen, T.; Altmann, K.-H. Chem. Eur. J. 2015, 21, 8403.

(9) For examples of preparation of allylic TCAIs, see: (a) Debbarma, S.; Bera, S. S.; Maji, M. S. J. Org. Chem. 2016, 81, 11716. (b) Das, D.; Halder, J.; Bhuniya, R.; Nanda, S. Eur. J. Org. Chem. 2014, 5229. (c) Ghosh, A. K.; Cheng, X.; Bai, R.; Hamel, E. Eur. J. Org. Chem. 2012, 4130. (d) Cui, Y.; Tu, W.; Floreancig, P. E. Tetrahedron 2010, 66, 4867.

(10) In the case of preparing glycosyl TCAIs, the mainly used base/solvent combination is $\mathrm{NaH} / \mathrm{CH}_{2} \mathrm{Cl}_{2}$. For examples of the papers, see: (a) Lee, A. M. M.; Painter, G. F.; Compton, B. J.; Larsen, D. S. J. Org. Chem. 2014, 79, 10916. (b) Ganesh, N. V.; Fujikawa, K.; Tan, Y. H.; Stine, K. J.; Demchenko, A. V. Org. Lett. 2012, 14, 3036. (c) Dieskau, A. P.; Plietker, B. Org. Lett. 2011, 13, 5544. (d) Boonyarattanakalin, S.; Liu, X.; Michieletti, M.; Lepenies, B.; Seeberger, P. H. J. Am. Chem. Soc. 2008, 130, 16791.

(11) For preparation of Bn-TCAI, see: (a) Ionescu, C.; Sippelli, S.; Toupet, L.; Barragan-Montero, V. Bioorg. Med. Chem. Lett. 2016, 26, 636. (b) Wallach, D. R.; Stege, P. C.; Shah, J. P.; Chisholm, J. D. J. Org. Chem.
2015, 80, 1993. (c) Kato, D.; Mitsuda, S.; Ohta, H. J. Org. Chem. 2003, 68,7234 .

(12) For preparation of PMB-TCAI, see: (a) Kuroda, Y.; Harada, S.; Oonishi, A.; Kiyama, H.; Yamaoka, Y.; Yamada, K.; Takasu, K. Angew. Chem. Int. Ed. 2016, 55, 13137. b) Liu, C.; Richards, M. R.; Lowary, T. L. Org. Biomol. Chem. 2011, 9, 165.

(13) For examples of preparation of allylic TCAIs, see: (a) Porter, M. R.; Shaker, R. M.; Calcanas, C.; Topczewski, J. J. J. Am. Chem. Soc. 2018, 140, 1211. (b) Martinez-Alsina, L. A.; Murray, J. C.; Buzon, L. M.; Bundesmann, M. W.; Young, J. M.; O’Neill, B. T. J. Org. Chem. 2017, 82, 12246. (c) Mwenda, E. T.; Nguyen, H. M. Org. Lett. 2017, 19 , 4814. (d) Sharif, S. A. I.; Calder, E. D. D.; Delolo, F. G.; Sutherland, A. J. Org. Chem. 2016, 81, 6697.

(14) For examples of preparation of glycosyl TCAIs, see: (a) Lu, Y.-J.; Lai, Y.-H.; Lin, Y.-Y.; Wang, Y.-C.; Liang, P.-H.J. Org. Chem. 2018, 83, 3688 (b) Mukherjee, M. M.; Ghosh, R. J. Org. Chem. 2017, 82, 5751. (c) Goto, K.; Sawa, M.; Tamai, H.; Imamura, A.; Ando, H.; Ishida, H.; Kiso, M. Chem. Eur. J. 2016, 22, 8323. (d) Kong, L.; Almond, A.; Bayley, H.; Davis, B. G. Nat. Chem. 2016, 8, 461.

(15) Yamada, K.; Fujita, H.; Kitamura, M.; Kunishima, M. Synthesis 2013, 45, 2989.

(16) We also examined the use of cyclohexane and petroleum ether as reaction solvents. However, both results were inferior to that using hexane. For more details, see page S17-18 of the supporting information.

(17) (a) Takeuchi, Y.; Ono, Y.; Hisanaga, N.; Kitoh, J.; Sugiura, Y. Br. J. Ind. Med. 1980, 37, 241. (b) Takeuchi, Y.; Ono, Y.; Hisanaga, N. Clin. Toxicol. 1981, 18, 1395.

(18) Dixon, N. Filtration \& Separation 2007, 44, 18.

(19) (a) Eastman, H. E.; Jamieson, C.; Watson, A. J. B. Aldrichimica Acta 2015, 48, 51. (b) Prat, D.; Hayler, J.; Wells, A. Green Chemistry 2014 $16,4546$.

(20) General synthetic procedure of p-methoxybenzyl 2,2,2trichloroacetimidate [PMB-TCAI (2)] in heptane: To a suspension of PMBOH (1.00 g, $7.24 \mathrm{mmol}$ ) and $\mathrm{Cl}_{3} \mathrm{CCN}$ (1.15 g, 7.97 $\mathrm{mmol})$ in heptane $(18 \mathrm{~mL})$ was added DBU $(110 \mathrm{mg}, 723 \mu \mathrm{mol})$ at $0{ }^{\circ} \mathrm{C}$. After the suspension became a solution (actual reaction time $=25 \mathrm{~min}$ ), heptane $(18 \mathrm{~mL})$ and saturated aq $\mathrm{NH}_{4} \mathrm{Cl}(18 \mathrm{~mL})$ were added to the reaction mixture. The separated heptane layer was washed with saturated aq $\mathrm{NH}_{4} \mathrm{Cl}(18 \mathrm{~mL})$ and dried over $\mathrm{Na}_{2} \mathrm{SO}_{4}$. Filtration of the $\mathrm{Na}_{2} \mathrm{SO}_{4}$, concentration of the filtrate under reduced pressure gave PMB-TCAI (2) (2.01 g, 99\%) as a colorless oil. The ${ }^{1} \mathrm{H}$ and ${ }^{13} \mathrm{C}$ NMR spectra of 2 were in good agreement with the literature data. ${ }^{22}{ }^{1} \mathrm{H} \mathrm{NMR}\left(400 \mathrm{MHz}, \mathrm{CDCl}_{3}, 24^{\circ} \mathrm{C}\right) \delta .8 .36(\mathrm{br} \mathrm{s}, 1 \mathrm{H})$, $7.37(\mathrm{~d}, J=8.7 \mathrm{~Hz}, 2 \mathrm{H}), 6.91(\mathrm{~d}, J=8.7 \mathrm{~Hz}, 2 \mathrm{H}), 5.28(\mathrm{~s} 2 \mathrm{H}), 3.82(\mathrm{~s}$, $3 \mathrm{H}) . ;{ }^{13} \mathrm{C} \mathrm{NMR}\left(101 \mathrm{MHz}, \mathrm{CDCl}_{3}, 24{ }^{\circ} \mathrm{C}\right) \delta .162 .8,159.9,129.9$ (2C), 127.7, 114.1 (2C), 91.6, 70.8, 55.4.

(21) As in the syntheses of $\mathbf{1}$ and 2, the reaction mixtures for $\mathbf{4 a - f , ~ 5 , ~ 6 , ~}$ and $\mathbf{7}$ were initially suspensions, and then gradually became clear solutions (see pages S29-39 of the supporting information). All obtained products were stainless. We also confirmed that $\mathbf{4 a}, \mathbf{4 e}$ and 6 could also be preserved at $-10{ }^{\circ} \mathrm{C}$ for more than one month.

(22) Tokuyama, H.; Okano, K.; Fujiwara, H.; Noji, T.; Fukuyama, T. Chem. Asian J. 2011, 6, 560. 